\title{
Game Analysis of SME Financing
}

\author{
Pingzhong Lin \\ School of Finance and Economics, Jimei University, Xiamen, China \\ Email: 13906000926@163.com
}

Received July $31^{\text {st }}$, 2012; revised September $26^{\text {th }}$, accepted October $15^{\text {th }}, 2012$

\begin{abstract}
The SMEs (small and medium-sized enterprises) play important role in the economy. However, the financing problem is a big difficulty, which has plagued the SMEs' development. Information asymmetry is the main reason for the SMEs' gaining funds so hard. The information asymmetry between banks and enterprises is that banks do not know the operating conditions and credit situation of SMEs. Then, to some extent, the banks are reluctant to support credit for businesses under the circumstance of lacking appropriate information, resulting in a "credit crunch" behavior. Therefore, the main measures of solving SMEs' financing difficulty are to overcome the information asymmetry in the process of SME financing by establishing effective information mechanisms, the credibility and restraint mechanisms, strengthening the construction of credit rating agencies, and promoting the mutual exchange of information.
\end{abstract}

Keywords: Credit Crunch; Game; Information Asymmetry; Adverse Selection

\section{Introduction}

In financing activities, information asymmetry between SMEs and investors is widespread. SMEs own relatively complete information about their future profitability. Whereas, the investors are often difficult to fully grasp the future profitability of SMEs, which means that they have incomplete information (Gao, 2011). This paper analyzes SMEs' financing problem from two perspectives: dynamic game of complete information and dynamic game of incomplete information. On the basis of the above analysis, it tries to identify the main reasons and viable solutions to change the status quo in SME financing.

\section{A Dynamic Game of Complete Information}

\section{The Game's Basic Assumptions}

1) The players: banks, small and medium enterprises. Both banks and SMEs are rational "economic man", whose pursuits are maximizing their own interests;

2) If there were enterprises in default on a loan, an efficient judicial system would safeguard the lender's normal interests, and the investigation cost of bank would be low and counted as zero;

3) Both sides of the players conduct dynamic game. It means that one party may act on camera according to the other party's action;

4) The players have the entire information about their own possible benefit in each state during the game. In other words, we are talking about a dynamic game of complete information.

\section{The Process of Game Development}

1) First, we assume credit market with complete information is the ideal state. If borrowers were in debt default, an efficient judicial system would solve the problem quickly. Meantime, the investigation cost of bank is low and counted as zero.

The payoff matrix of bank and enterprise is:

a) If bank did not provide capital for SME, then both sides' interests would be zero. The revenue collection is $(0,0)$;

b) If bank provided capital for SME and the enterprise returned the loan repayment in time, then the situation would be win-win cooperation. The revenue collection is $(+1,+1)$;

c) If bank provided capital for SME, the enterprise refused to return the loan repayment and bank borne loss. Then the enterprise obtained interests exclusively and bank lost its principal. The revenue collection is $(+2,-1)$;

d) If bank provided capital for SME, the enterprise refused to return the loan repayment and bank dun to enterprise. At this point, the profit of company would be zero for its punishment, because it did not fulfill its responsibilities. And bank's interests would be protected. The revenue collection is $(0,+1)$.

We get the following Nash equilibrium: Bank provides capital to SME and the enterprise returns the loan repayment. The revenue collection is $(+1,+1)$, both participants in the development process are beneficiaries, and the situation would be win-win cooperation.

2) Due to information asymmetry, the above ideal state is difficult to meet in our real life. Owing to SMEs with the characteristics of lacking assets and collateral, banks cannot obtain sufficient income by means of auction of mortgaged property (Chen \& Tang, 2001). Therefore, the only solution is to resort to the judicial system. However, judicial system in China is inefficient and expensive at present. The inefficient judicial system is likely to make the bank cannot recover costs or pay higher costs when the bank recourse to law after company defaults.

Therefore, we make the second assumption: we assume that banks should pay high transaction costs when it resorts to the judicial system after enterprise defaults. The transaction cost is set to 0.5 . So the bank's interests is 0.5 , the company's interests is 1.5 when the enterprise refused to return the loan repayment and bank dun to the enterprise.

The payoff matrix of bank and enterprise is:

a) If bank did not provide capital for SME, then both sides' interests would be zero. The revenue collection is $(0,0)$; 
b) If bank provided capital for SME and the enterprise returned the loan repayment in time, then the situation would be win-win cooperation. The revenue collection is $(+1,+1)$;

c) If bank provided capital for SME, the enterprise refused to return the loan repayment and bank borne loss. Then the enterprise obtained interests exclusively and bank lost its principal. The revenue collection is $(+2,-1)$;

d) If bank provided capital for SME, the enterprise refused to return the loan repayment and bank dun to enterprise. At this point, the inefficient judicial system would make the company still gain interests of 1.5, and the bank's interests would be protected to some extent as 0.5 . The revenue collection is $(+1.5$, $+0.5)$.

Examine the pattern of this game between the bank and the enterprise, we will find that the original equilibrium is broken. The new Nash equilibrium should be $(0,0)$. That is the banks refused to offer money from the very beginning.

This phenomenon is not uncommon in real life. As a result of Chinese judicial system's inefficiency when it duns for arrearage, bank can get back little money but pays high transaction cost. In other words, the desired effect cannot be achieved when bank pursuits debt recovery through the judicial system. The expected return of dunning to enterprise, for the bank, is less than debt recovery cost in this case. Then the bank tends to not pursue the matter, and make its threat become incredible. Therefore, when the company knows the bank's rational choice, its best option is "deadbeat". Thus, in order to avoid losses $(-1)$, banks would choose not to trust SMEs and retain principal when they know the company would refuse to repay the debts. The best choice of banks is not offer capital to SMEs. It is the so called "credit crunch" when banks expected to lose their principal. In this circumstance, Nash equilibrium of the dynamic game between the bank and the SME becomes $(0,0)$. At this time, in order to guarantee its principal safe, the bank would like to invest in large enterprises, who own less credit risk, instead of SME (Lu, 2005). This is why SME loans accounted for a relatively small proportion in total corporate loans.

\section{Equilibrium Analysis}

Through the above analysis of game, we know that bank could not recover its lost totally in time when the enterprise chose to break the contract. The bank inclined to select "credit crunch". Thus, SMEs cannot gain enough funds to obtain their own development. At the meantime, standard financial system has not been set up generally in SMEs, which makes banks face extremely high costs of searching for business information of SMEs. The small scale of most SMEs financing creates the small income of bank. The bank's cost-profit ratio (profits/costs, costs include the cost of searching for information and the amortized cost of non-performing loans of SMEs) from SMEs is much lower than the one from large enterprises. Therefore, bank credit funds flow to the large enterprises eventually. Thence, standard financial system should be set up in SMEs to overcome the information asymmetry in the process of SME financing on the one side, and effective judicial system should be established in society to increase the costs of breaking contract on the other hand. Increasing bank's cost-profit ratio from SMEs would make part of bank credit funds flow from the large enterprises to the SMEs. This process would not stop until the two cost-profit ratios are equal. That is capital liquidity maintains a balanced state.

\section{A Dynamic Game of Incomplete Information}

\section{The Game's Basic Assumptions}

1) The players: banks, small and medium-sized enterprises. SMEs are divided into two types: enterprises with good economic efficiency and ones with poor economic efficiency. The good ones can repay all the bank loans on time, whereas the poor ones would make banks suffer losses.

2) The revenue of bank from offering capital is set to $\mathrm{Rg}$, and $\operatorname{Rg}>0$. The revenue of bank from offering capital to enterprises with good economic efficiency is set to R1, R1 $>0$; the interests of enterprises who choose repudiation is set to $\mathrm{R} 2$, $\mathrm{R} 2>0$; the revenue of bank from offering capital to enterprises with poor economic efficiency is set to $\mathrm{Rb}, \mathrm{Rb}<0$.

\section{The Process of Game Development}

1) Whether the SMEs apply for loans from banks or not in this game.

Game tree can be used to represent this incomplete information game. The second layer of this decision tree contains two decision nodes, which means that information of business situation owned by bank is incomplete. In other words, the bank does not know which path reflects the true operating situation of the SMEs. Then banks cannot make decision separately according to the two different cases. There are three possibilities for the banks on the promise of the enterprises apply for a loan. If banks choose to accept the application, they may get a profit (enterprises with good economic efficiency) and may suffer a loss (enterprises with bad economic efficiency). If the banks choose not to accept the application, they would miss the opportunity of gain. As a result, the banks need to assess the probabilities of enterprises' efficiency before they make the decision.

$\mathrm{R} 2>0$, means that enterprises with poor economic efficiency can gain benefits through defrauding banks of funds. Therefore, it is easy to know that enterprises will apply for a loan whether they are in good or poor management state.

Whether the banks accept the SMEs' application for loans or not in this game.

On the promise of enterprises apply for a loan, we use $\mathrm{P}(\mathrm{G} \mid \mathrm{A})$ stands for the conditional probability of enterprises with good economic efficiency and $\mathrm{P}(\mathrm{B} \mid \mathrm{A})$ stands for the conditional probability of the ones with bad economic efficiency. $P(G)$ and $P(B)$ stand for the probabilities of enterprises in good and in bad management state respectively (both probabilities only can be estimated by empirical data or general knowledge from the average case). $\mathrm{P}(\mathrm{A} \mid \mathrm{G})$ and $\mathrm{P}(\mathrm{A} \mid \mathrm{B})$ stand for the conditional probabilities of enterprises in good and in bad management state respectively when they apply for loans. Based on the above analysis, we know:

$$
\mathrm{P}(\mathrm{A} \mid \mathrm{G})=\mathrm{P}(\mathrm{A} \mid \mathrm{B})=1
$$

According to Bayes' rule:

$$
\begin{aligned}
& \mathrm{P}(\mathrm{G} \mid \mathrm{A})=\mathrm{P}(\mathrm{G}) \mathrm{P}(\mathrm{A} \mid \mathrm{G}) /(\mathrm{P}(\mathrm{G}) \mathrm{P}(\mathrm{A} \mid \mathrm{G})+\mathrm{P}(\mathrm{B}) \mathrm{P}(\mathrm{A} \mid \mathrm{B})) \\
& \text { From } P(B \mid A)=1-P(G \mid A) \text {, it is easy to find } P(B \mid A) \text {. } \\
& \mathrm{P}(\mathrm{G} \mid \mathrm{A}) \\
& =P(G) P(A \mid G) /(P(G) P(A \mid G)+P(B) P(A \mid B)) \\
& =\mathrm{P}(\mathrm{G}) /(\mathrm{P}(\mathrm{G})+\mathrm{P}(\mathrm{B}))=\mathrm{P}(\mathrm{G})
\end{aligned}
$$


Similarly: $\mathrm{P}(\mathrm{B} \mid \mathrm{A})=\mathrm{P}(\mathrm{B})$

This means that the probability of enterprises in good management state on the market is equal to the one on the credit market, and so do the probability of ones in bad management.

Since banks cannot know accurately the status of the business application, they can only make decisions by calculating the expected return E(R) based on the applicant's probability of management situation.

According to the banks' experience and judgment, we set up: $\mathrm{P}(\mathrm{G})=\mathrm{p}$

So, on the promise of the banks accept the application, the expected payment is:

$$
E(R)=p \cdot R g+(1-p) \cdot R b=(R g-R b) \cdot p+R b
$$

Conditions of banks choose to lend:

$$
E(R)=(R g-R b) \cdot p+R b>0
$$

Namely:

$$
\mathrm{p}>(-\mathrm{Rb}) /(\mathrm{Rg}-\mathrm{Rb})
$$

Accordingly, Conditions of banks choose not to lend:

$$
E(R)=(R g-R b) \cdot p+R b<0
$$

Namely:

$$
\mathrm{P}<(-\mathrm{Rb}) /(\mathrm{Rg}-\mathrm{Rb})
$$

This is a pooling equilibrium, means that banks would not like to offer credit until there is an overwhelming majority of enterprises with good economic efficiency. As a result, when the probability that $\mathrm{P}<(-\mathrm{Rb}) /(\mathrm{Rg}-\mathrm{Rb})$ on the circumstance of economic downturn and the overall social credit deterioration, the bank will refuse to provide capital to evade risks. This "credit crunch" behavior makes the SMEs raise funds with great difficulty.

Since it is difficult to see the $p>(-R b) /(R g-R b)$ conditions on the average in reality, the banks mistrust the SMEs even if $(-\mathrm{Rb}) /(\mathrm{Rg}-\mathrm{Rb})$ is indeed smaller than $\mathrm{p}$. That is, as long as the banks think $\mathrm{P}<(-\mathrm{Rb}) /(\mathrm{Rg}-\mathrm{Rb})$, they would refuse the SMEs application for loans. This is a complete market failure. Of course, market efficiency can be achieved partially if the bank still takes mixed strategy (make decision with a certain probability randomly) under the circumstance of lacking confidence in the SMEs. In this case, the market is lack of efficiency. This explains why SME loans accounted for a relatively small proportion in total corporate loans, even there are so many documents issued by the State Council and the CBRC (China Banking Regulatory Commission) requiring banking institutions to increase more loans for the SMEs. Apparently, the incomplete information, under certain circumstances, indeed brings about a significant impact on the market efficiency.

In addition, in the case of asymmetric information, bank needs to pay costs in the process of searching information. The direct costs of information production include manpower cost, fund cost, generating from the process of information searching, screening, treating and processing, which directly affect the economic efficiency of commercial banks credit activities. The indirect costs of information production include the loss of declining efficiency, the loss of decreasing service level and the loss of reducing market share (Zhao, 2009). The level of information costs is correlated positively with the degree of infor- mation asymmetry. The higher degree of information asymmetry is, the higher information cost is produced. Investors must be requiring a higher return on investment as compensation.

\section{The Way of Easing “Credit Crunch” from the above Analysis of Game}

\section{National Credit Rating Agencies Must Be Built}

Nowadays, the development of Chinese credit rating agency is not standard. Banks can only search for SMEs' information from within, as a result of disbelieving rating results from credit rating agency, which increases lending costs. In fact, rating by professional credit rating agencies is much cost-effective than establishing the credibility on the bank's own. Therefore, government should support the establishment of national professional rating agencies. Meantime, foreign large-scale rating agencies should be introduced timely as well. These behaviors would reduce the financial institutions' high costs of organizing their own rating of SMEs. Rational bank is willing to cooperate with professional rating agencies to reduce its information costs for SMEs. After the text edit has been completed, the paper is ready for the template. Duplicate the template file by using the Save As command, and use the naming convention prescribed by your journal for the name of your paper. In this newly created file, highlight all of the contents and import your prepared text file. You are now ready to style your paper.

\section{National Information Sharing Mechanism Must Be Built}

Governments should promote the establishment of a national information sharing system of SMEs. This can increase the SMEs' loss of corporate defaults and cut financial institutions' high costs of building their own information systems for SMEs, and promote the development of the socioeconomic. Establishing and maintaining expenses of information systems can be sponsored by banks, guarantee agencies, trusts, and private equity funds. Financial institutions can identify the borrower's credit more effectively by taking advantage of shared information systems. On the one hand, the contract breaching cost of defaulter has been increased and the financing cost of trustworthy person has been reduced; on the other hand, the selecting costs of the bank before lending money has been cut down as well. Then, the bank's credit assets quality will increase as the structure of information between banks and enterprises improved. Credit risk can be controlled effectively and financial stability can be maintained (Hoff, 1990).

\section{Credibility Restraint Mechanisms Must Be Built}

Most SMEs hope they can obtain loans from bank many times in reality. According to reputation model of Kreps Milgrom and Wilson Roberts (1982), incomplete information can lead to cooperative effects in finite repeated games. Because both parties, in order to obtain long-term benefits from cooperating, do not want to prematurely reveal their nature. Therefore, only those enterprises, who do not want long-term development will break contract prematurely.

In modern society, long-term business relationship between businesses and banks should be constituted, especially for the SMEs who pursue long-term development. In the case of repeated games, the poor credit record will be entered in informa- 
tion database if the company defaults. When the defaulter reapplies for credit, he would face up to higher interest rate to make up the cost of default, or even be rejected from financing. In the long term, to be faithful is conductive to reduce the cost of borrowing, maintain a good relationship between banks and enterprises, and promote the company's long-term development. Banks can assess the borrower's credit situation from historical records and regulate the requirements on collateral accordingly.

\section{Perfecting the Judicial System and Improving Judicial Efficiency}

The pattern of dynamic game between banks and enterprises will be changed by high transaction costs and inefficient judicial process. This kind of allocation of resources is not effective. Influenced by relatively minor loans and more expensive transaction costs, SMEs are more likely face credit crunch. Only by being aware of the legal knowledge and judicial procedures, adopting a proper attitude to the threat of bank can enterprises make sensible decision.

Under the circumstance of sound legal system and efficient judicial process, the threat of honoring liability becomes more credible for the SMEs. Thus, the result of game may turn out to be a win-win state (Ghatak, 1999). In other words, enterprise tends to fulfill the obligation. Both parties have benefit and there is a Pareto Optimality.

\section{Strengthening Information Exchange and Promoting the Long-Term Cooperation between Banks and SMEs}

The financial system must be established and improved in enterprises to ensure financial information is truthful, accurate and complete, enhance the transparency of financial information. A good image should be established by means of passing real and complete information to the bank through effective way. From long-term perspective, cooperative relationship between banks and enterprises should be established. This relationship is helpful to reduce financing costs, increase credit profits, evade credit risks, and enhance the competitiveness of SMEs in China.

\section{REFERENCES}

Chen, Y., \& Tang, Z. Y. (2001). Game analysis of commercial bank credit. Studies of International Finance, 4, 23-28.

Gao, H. Y. (2011). Western economics micropart. Beijing: Renmin University of China Press.

Ghatak, M., \& Timothy, G. (1999). The economics of lending with joint liability: Theory and practice. Journal of Development Economics, 60, 195-228. doi:10.1016/S0304-3878(99)00041-3

Hoff, K., \& Joseph, E. S. (1990). Imperfect information and rural credit markets: Puzzles and policy. World Bank Economic Review, 4, 235 250. doi: $10.1093 /$ wber/4.3.235

Kreps, M. R., \& Wilson, R. (1982). Reputation and imperfect information. Economic Theory, 27, 253-279. doi:10.1016/0022-0531(82)90030-8

Lu, L. X., Wang, J. T., \& Yu, Z. W. (2005). Banks and SMEs credit game analysis. Jinan Finance, 3, 36-37.

Zhao, G. X. (2009). Bank and the game, information costs and information production efforts of commercial banks. Productivity Research, 22, 58-60 